\title{
Increased platelet aggregate formation in patients with chronic airflow obstruction and hypoxaemia
}

\author{
J A Wedzicha, D Syndercombe-Court, K C Tan
}

\begin{abstract}
Platelet aggregate formation in vivo was assessed by means of the platelet aggregate ratio and from platelet release products ( $\beta$ thromboglobulin, platelet factor 4 , thromboxane $B_{2}$ ) in 23 patients with chronic airflow obstruction with and without hypoxaemia and in 10 control subjects without respiratory disease. Eight of the 11 hypoxaemic patients were having long term oxygen therapy. The platelet aggregate ratio was lower in the hypoxaemic patients $(0.88$ (SE 0.03$))$ than in the non-hypoxaemic $(0.97(0.01))$ and control groups $(1.00(0.02))$, and there was a trend to lower aggregate ratios in the more hypoxaemic patients. Platelet release products in the peripheral venous blood were not increased in the patients or control subjects. Platelet behaviour is altered in chronic hypoxaemia and this enhanced platelet activity could contribute to the pulmonary vascular damage found in these patients through direct effects or mediator release.
\end{abstract}

Various factors are known to contribute to pulmonary hypertension in patients with chronic hypoxaemic lung disease, including hypoxaemia, structural changes in the pulmonary arterioles, polycythaemia, an increased blood volume, and mechanical factors (by an increase in airway resistance and thus mean alveolar pressure). ${ }^{1}$ Platelets play an important part in thrombosis and vascular damage, but their role in the development of pulmonary vascular changes in patients with chronic hypoxaemia is uncertain.

We have previously shown that platelets from patients with chronic hypoxaemia are larger, with a greater mean volume. ${ }^{2}$ These larger platelets are haemostatically more active and show an increased tendency to aggregate; platelet aggregation could have contributed to the apparent increase in platelet volume. ${ }^{34}$ Chronic hypoxaemia is associated with a decrease in platelet survival time, suggesting increased platelet consumption. ${ }^{5}$ Platelet aggregation, when assessed by in vitro methods, is increased in patients with chronic hypoxaemia and chronic airflow obstruction. ${ }^{6}$

We have investigated platelet function further in patients with chronic airflow obstruction with and without hypoxaemia, measuring platelet aggregate formation in vivo in addi- tion to blood concentrations of various platelet release products.

\section{Methods}

We studied 23 patients with chronic airflow obstruction and a wide range of arterial blood gas tensions. Eleven of the patients (mean (SD) age $66(6.5)$ years) were hypoxaemic (arterial oxygen tension $\left(\mathrm{PaO}_{2}\right) 8 \mathrm{kPa}$ or less) and 12 patients (mean age $62(6.6)$ years) had no hypoxaemia. Eight of the hypoxaemic group were having long term oxygen therapy, with standard instructions to use oxygen for 15 hours daily. All the patients were stable clinically with no exacerbations of their airflow obstruction for two weeks before the study. None of the patients was taking any medication known to affect platelet function. Ten control subjects from the same age range (mean age 60 $(7 \cdot 1)$ years) with no evidence of respiratory disease were also recruited. The study was approved by the ethics committees of the Royal Brompton National Heart and Lung Hospitals and the London Hospital.

Sampling for the platelet studies was performed under standardised conditions; no coffee, tea or theophylline was taken on the day of the study. The patients and control subjects attended the laboratory in the morning and rested for at least an hour. Blood was then sampled by direct venepuncture with a vacutainer, without the use of a tourniquet, from a large vein in the antecubital fossa.

The platelet aggregate ratio, a quantitative measure of platelet aggregate formation in vivo, was measured by a method modified from that described by Wu and Hoak $^{7}: 1.5 \mathrm{ml}$ of blood was taken into a vacutainer filled with $3.5 \mathrm{ml}$ of $4.5 \mathrm{mM} \mathrm{Na}_{2} \mathrm{HPO}_{4}, 1.6 \mathrm{mM} \mathrm{KH} \mathrm{KO}_{4}$, and $5.8 \mathrm{mM}$ tripotassium EDTA in normal saline containing $0 \cdot 15 \%$ formaldehyde. A further $1.5 \mathrm{ml}$ of the blood sample was taken into a similar tube without the addition of formaldehyde. Any aggregates formed as a result of exposure of susceptible platelets to a particular microenvironment are fixed in the formalinEDTA mixture but broken up by the high concentration of EDTA in the "EDTA alone" mixture. The platelet aggregate ratio is given by the ratio of the platelet count in the formalin-EDTA mixture to that in the EDTA mixture, the count having been corrected for packed cell volume. In the absence of platelet aggregates the platelet aggregate ratio approaches 1.0 .

Three millilitres of blood were taken into

EDTA for a routine haematology profile, a
D Syndercombe-Court

Reprint requests to:

Dr Wedzicha

Accepted 17 April 1991 
Table 1 Clinical details of the patients

\begin{tabular}{|c|c|c|c|c|}
\hline & \multicolumn{2}{|c|}{ Group (mean (SE)) } & \multirow[b]{2}{*}{$\begin{array}{l}\text { Mean } \\
\text { difference }\end{array}$} & \multirow[b]{2}{*}{$\begin{array}{l}95 \% \text { confidence } \\
\text { limits }\end{array}$} \\
\hline & $\begin{array}{l}\text { Non-hypoxaemic } \\
n=12\end{array}$ & $\begin{array}{l}\text { Hypoxaemic } \\
n=11\end{array}$ & & \\
\hline $\begin{array}{l}\text { Age }(\mathrm{y}) \\
\mathrm{PaO}_{2}(\mathrm{kPa}) \\
\mathrm{PaCO}_{2}(\mathrm{kPa}) \\
\mathrm{FEV}_{1}(\mathrm{l}) \\
\mathrm{FVC}(\mathrm{l}) \\
\text { Packed cell volume }\end{array}$ & $\begin{array}{l}62(\text { SD } 7) \\
9 \cdot 7(0 \cdot 2) \\
5 \cdot 2(0 \cdot 2) \\
0.77(0 \cdot 09) \\
1.89(0 \cdot 21) \\
0.417(0.011)\end{array}$ & $\begin{array}{l}66(\text { SD } 6) \\
6 \cdot 5(0 \cdot 3) \\
6 \cdot 6(0 \cdot 3) \\
0 \cdot 83(0 \cdot 10) \\
1.92(0 \cdot 13) \\
0.514(0 \cdot 017)\end{array}$ & $\begin{array}{l}-4 \\
+3.2 \\
-1.4 \\
-0.06 \\
-0.03 \\
-0.096\end{array}$ & $\begin{array}{l}-10,+2 \\
+2 \cdot 5,+3 \cdot 9 \\
-2 \cdot 1,-0 \cdot 7 \\
-0.35,+0.23 \\
-0.55,+0.49 \\
-0.138,-0.054\end{array}$ \\
\hline
\end{tabular}

$\mathrm{PaO}_{2}$-arterial oxygen tension; $\mathrm{PaCO}_{2}$-arterial carbon dioxide tension; $\mathrm{FEV}_{1}$ - forced expiratory volume in one second; FVC-forced vital capacity.

Coulter counter being used (model S Plus IV). Plasma fibrinogen concentrations were measured by the method of Clauss. ${ }^{8}$ Ten millilitres of blood was taken into Thrombotect (Abbott Laboratories) tubes for estimation of platelet granule release products. These samples were prepared according to recommended procedures (PF4 RIA, Abbott Laboratories Diagnostics Division). Plasma $\beta$ thromboglobulin was measured by radioimmunoassay with a commercial kit (Amersham International) and platelet factor 4 with a radioimmunoassay kit (Abbott Laboratories). Thromboxane $\mathrm{A}_{2}$ was measured as its stable derivative thromboxane $B_{2}$ with a radioimmunoassay kit (Amersham International). Plasma samples were prepared from $5 \mathrm{ml}$ of

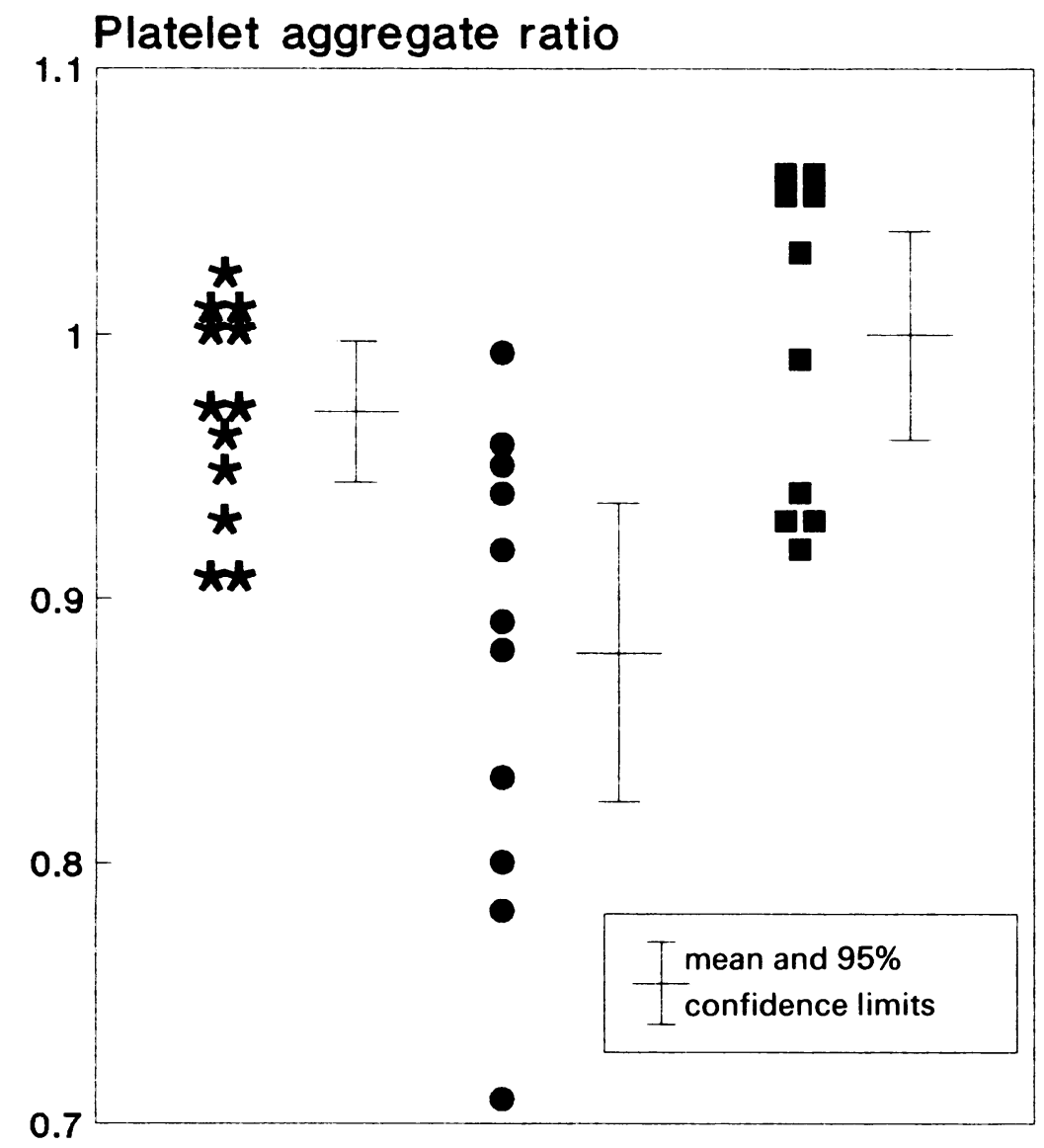

Non-hypoxaemic Hypoxaemic Normal controls

Figure 1 Platelet aggregate ratios in control, non-hypoxaemic, and hypoxaemic groups: individual values with means and $95 \%$ confidence limits. blood collected into an EDTA-indomethacin solution as recommended (BTG radioimmunoassay kit, Amersham International).

The $\mathrm{FEV}_{1}$ and forced vital capacity (FVC) were measured with a dry spirometer (PK Morgan). Blood was taken from the radial artery in the patients and analysed for gas tensions on a Radiometer ABL 1 analyser. Blood carboxyhaemoglobin concentrations were estimated with a Radiometer OSM2 Hemoximeter.

\section{STATISTICAL ANALYSIS}

Student's unpaired (two tailed) $t$ test was used to compare values from the hypoxaemic and non-hypoxaemic groups and results are presented as the $95 \%$ confidence intervals of the differences. One way analysis of variance was used to compare the laboratory measurements in the three study groups. Analysis of $\beta$ thromboglobulin concentrations was made on log transformed values because of their skewed distribution.

\section{Results}

The clinical details of the hypoxaemic and nonhypoxaemic patients are compared in table 1. The hypoxaemic patients had a lower $\mathrm{PaO}_{2}$ $(\mathrm{p}<0.001)$ and a higher arterial carbon dioxide tension $\left(\mathrm{PaCO}_{2}\right)(\mathrm{p}<0.001)$ than the nonhypoxaemic group. All the non-hypoxaemic patients and control subjects were non-smokers and had carboxyhaemoglobin concentrations within the normal range (under $3 \%$ ). In the hypoxaemic group four patients had carboxyhaemoglobin concentrations in the range seen in smokers $(3 \cdot 2 \%-7 \cdot 8 \%)$, though only three were declared smokers. There was no significant difference in the forced expiratory volume in one second $\left(F E V_{1}\right)$ or forced vital capacity (FVC) between the two groups of patients, but the hypoxaemic patients had a higher packed cell volume $(p<0.001)$.

The platelet aggregate ratios for the three groups are shown in figure 1 . The ratio was lower in the hypoxaemic group (mean (SE) ratio $0.88(0.03))$ than in the non-hypoxaemic group $(0.97(0.01))$ or the control subjects $(1.0$ $(0.02))$. The mean difference $(95 \%$ confidence limits) between the hypoxaemic and the nonhypoxaemic patients was $-0.09(-0.15$, -0.03 ) and between the hypoxaemic and the control subjects $-0 \cdot 12(-0 \cdot 19,-0 \cdot 05)$. There was a trend for patients with lower platelet aggregate ratios to have lower $\mathrm{PaO}_{2}$ values (fig 2) and higher $\mathrm{PaCO}_{2}$ values. Within the hypoxaemic group there was no difference in mean platelet aggregate ratio between the four patients who had a carboxyhaemoglobin concentration greater than $3 \%$ (mean ratio 0.89 (SE 0.06)) and the seven patients with a blood carboxyhaemoglobin level below 3\% (mean ratio 0.87 (SE 0.03)), the mean difference being $0.02(95 \% \mathrm{CL}-0.02,0.06)$.

The concentrations of the platelet release products in the patients and control subjects are shown in table 2 . No differences were observed in the concentrations of $\beta$ thromboglobulin and, although there was a slight 
Figure 2 Relation of platelet aggregate ratio to arterial oxygen tension ( $\mathrm{PaO}_{2}$ ) for nonhypoxaemic ( $\star$ ) and hypoxaemic ( ) patients.

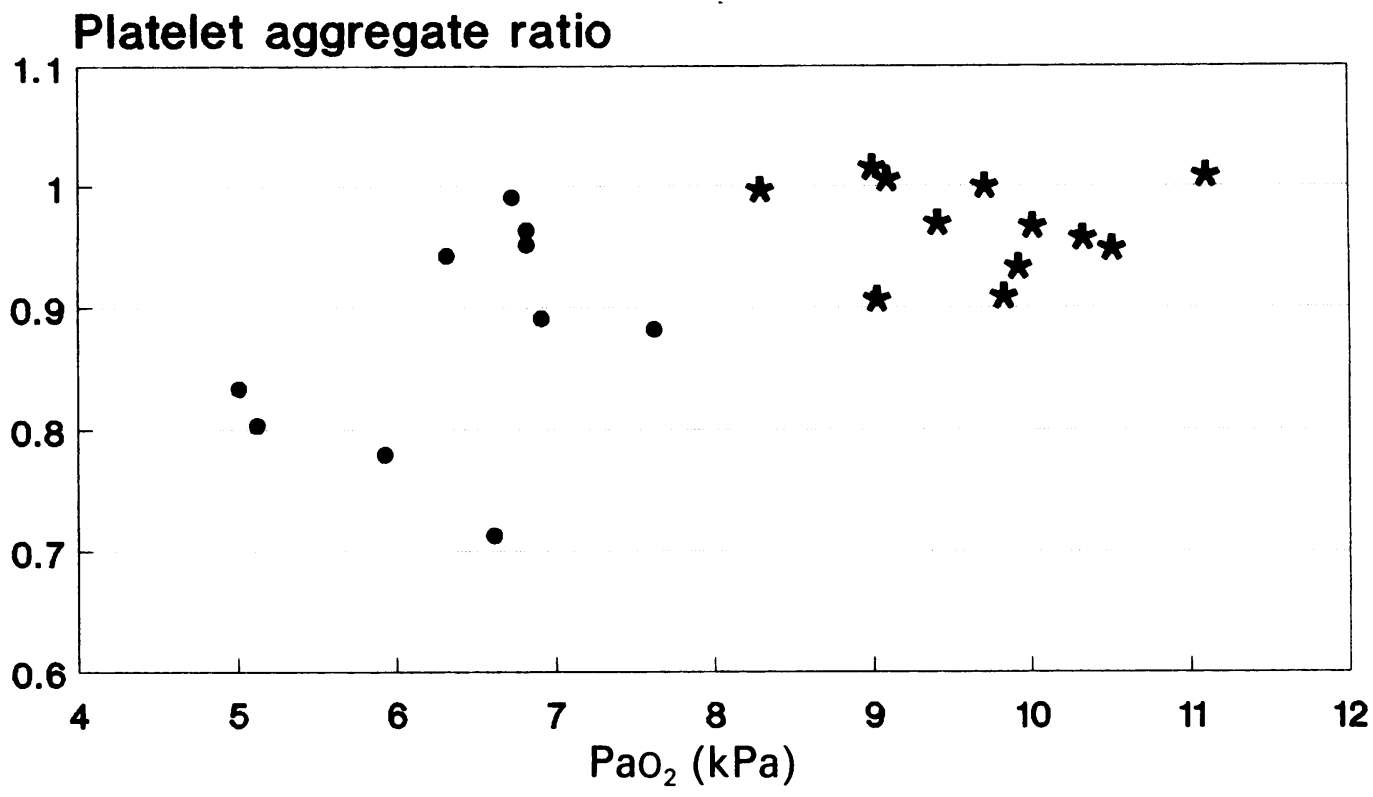

increase in platelet factor 4 in the hypoxaemic group, this was not significant. No differences were observed in thromboxane $B_{2}$ concentrations or in platelet counts. Blood fibrinogen concentrations were slightly higher in the hypoxaemic group but not significantly so.

\section{Discussion}

In this study the platelet aggregate ratio was lower in patients with chronic airflow obstruction and hypoxaemia than in patients without arterial hypoxaemia or in control subjects without respiratory disease. We found no effect of blood carboxyhaemoglobin concentration on platelet aggregate formation, though the number of smokers in the study was small. Cigarette smoking is associated with enhanced platelet activity ${ }^{9}$ and further studies are required to assess the effect of smoking on platelet function in hypoxaemic patients. Eight of the 11 hypoxaemic patients in this study were having long term oxygen therapy at home. As oxygen therapy can improve platelet survival in patients with chronic hypoxaemia, ${ }^{5}$ possibly oxygen therapy also reduced some of the changes in platelet aggregate ratios or release products in our patients.

The reduction in the platelet aggregate ratio suggests that patients with chronic hypoxaemia have more active platelets with an increased

Table 2 Laboratory investigations of subject groups

\begin{tabular}{|c|c|c|c|c|}
\hline & \multicolumn{3}{|c|}{ Group (mean (SE)) } & \multirow[b]{2}{*}{$p^{\star}$} \\
\hline & $\begin{array}{l}\text { Non-hypoxaemic } \\
n=12\end{array}$ & $\begin{array}{l}\text { Hypoxaemic } \\
n=11\end{array}$ & $\begin{array}{l}\text { Normal } \\
n=10\end{array}$ & \\
\hline Platelet aggregate ratio & $0.97(0.01)$ & $0.88(0.03)$ & $1.00(0.02)$ & $<0.001$ \\
\hline $\begin{array}{l}\beta \text { Thromboglobulin } \\
(\mathrm{ng} / \mathrm{ml}, \mathrm{GM}(95 \% \mathrm{CL}))\end{array}$ & $\begin{array}{l}39 \cdot 2 \\
(24 \cdot 9,61 \cdot 9)\end{array}$ & $\begin{array}{l}32 \cdot 3 \\
(22 \cdot 7,45 \cdot 8)\end{array}$ & $\begin{array}{l}30 \cdot 0 \\
(16.9,53 \cdot 5)\end{array}$ & 0.74 \\
\hline Platelet factor $4(\mathrm{ng} / \mathrm{ml})$ & $15.9(2.5)$ & $26 \cdot 1(3 \cdot 5)$ & $22 \cdot 1(3 \cdot 3)$ & 0.07 \\
\hline Thromboxane $B_{2}(\mathrm{pg} / \mathrm{ml})$ & $31.0(2.6)$ & $32.4(2 \cdot 3)$ & $28.7(2.0)$ & 0.58 \\
\hline Platelets $\left(\times 10^{9} / 1\right)$ & $306(22)$ & $268(20)$ & $246(16)$ & $0 \cdot 11$ \\
\hline Fibrinogen $(g / 1)$ & $2 \cdot 89(0 \cdot 14)$ & $3 \cdot 27(0 \cdot 10)$ & $3.05(0.08)$ & 0.07 \\
\hline
\end{tabular}

$\star$ One way analysis of variance.

GM-geometric mean. tendency to aggregate formation in the circulation. Platelet aggregate formation increased with worsening hypoxaemia and hypercapnia. Platelet activation in hypoxaemic patients may cause local effects on the pulmonary circulation. Pulmonary thromboembolism is frequently found at necropsy in patients with chronic lung disease, and increased platelet activity could contribute to these thrombotic events. ${ }^{10}$ Studies in rabbits exposed to simulated altitude showed platelet sequestration in the lung. ${ }^{11}$ Hypoxaemia may cause endothelial injury ${ }^{12}$ and this could further increase platelet aggregation in the lung. Platelet survival times are reduced in hypoxaemic patients, ${ }^{5}$ perhaps as a result of platelet aggregate formation in the circulation. Evidence from work with the isolated rat lung suggests that platelets may potentiate the hypoxic vasoconstrictor response of the pulmonary circulation and this may lead to pulmonary hypertension. ${ }^{13}$ In another study, however, platelet antiserum did not reduce the pulmonary vascular pressor response to hypoxia. ${ }^{14}$

Platelet aggregates formed in the circulation as a result of hypoxaemia may be trapped in the lung and lead to release of mediators from the active platelets. These may have actions on the pulmonary circulation and contribute to the development of pulmonary hypertension and cor pulmonale. Increased concentrations of $\beta$ thromboglobulin have been reported in a small number of patients with chronic airflow obstruction and hypoxaemia, ${ }^{15}$ but we found no significant increases in platelet release products in the peripheral venous blood in our hypoxaemic patients, though platelet factor 4 concentrations tended to be higher in this group. Our samples were taken from the systemic circulaproducts in the pulmonary circulation would be more relevant in these patients. Higher concentrations of $\beta$ thromboglobulin and thromboxane $B_{2}$ in the pulmonary vasculature than in the peripheral veins have been reported in patients with pulmonary hypertension. ${ }^{16} \mathrm{We}$ cannot, however, exclude the possibility that, tion and measurement of platelet release 
because of the small numbers in the study, there is not enough power to detect differences that may truly exist.

This study shows that platelet behaviour is altered in patients with chronic hypoxaemia. These active platelets may, through direct effects or mediator release, cause local pulmonary vascular damage and lead to the development of pulmonary hypertension. Modulation of platelet activity by oxygen or pharmacological methods might reduce pulmonary hypertension, but this needs to be determined.

1 Harris $\mathrm{P}$, Heath D. The human pulmonary circulation. Edinburgh: Churchill Livingstone, 1977:522-46.

2 Wedzicha JA, Cotter FE, Empey DW. Platelet size in patients with chronic airflow obstruction with and withou hypoxaemia. Thorax 1988;43:61-4.

3 Manucci PM, Sharp AA. Platelet volume and shape in relation to aggregation and adhesion. $\mathrm{Br} J$ Haematol 1967;13:604-17.

4 Thompson CB, Jakubowski JA, Quinn PG, Deykin D, Valeri CR. Platelet size as a determinant of platelet function. J Lab Clin Med 1983;101:205-13.

5 Johnson TS, Ellis JH Jr, Steele PP. Improvement of platelet survival time with oxygen in patients with chronic obstructive airway disease. Am Rev Respir Dis 1978;117: 255-7.
6 Cordova C, Musca A, Violi F, Alessandri C, Perrone A, Balsano F. Platelet hyperfunction in patients with chronic airways obstruction. Eur J Respir Dis 1985;66:9-12.

7 Wu KK, Hoak JC. A new method for the quantitative detection of platelet aggregates in patients with arterial insufficiency. Lancet 1974;ii:924-6.

8 Clauss A. Rapid physiological coagulation method in determination of fibrinogen. Acta Haematol 1957;17:237-46.

9 Lassila R, Seyberth HW, Haapanen A, Schweer H, Koskenvuo $M$, Laustiola $K E$. Vasoactive and atherogenic effects of cigarette smoking: a study of monozygotic twins discordant for smoking. Br Med J 1988;297:955-7.

10 Mitchell RS, Silvers GW, Dart GA, et al. Clinical and morphologic correlations in chronic airway obstruction. Am Rev Respir Dis 1968;97:54-62.

11 Gray GW, Bryan AC, Freedman MH, et al. Effect of altitude exposure on platelets. J Appl Physiol 1975;39:648-52.

$12 \mathrm{Kjeldsen} \mathrm{K}$, Thomsen HK. The effect of hypoxia on the fine structure of the aortic intima in rabbits. Lab Invest 1975;33:533-43.

13 Kivity S, Souhrada JF. Plasma and platelets potentiate a hypoxic vascular response of the isolated lung. $J$ Appl Physiol 1981;51:875-80.

14 Weir EK, Seavy J, Mlczoch J, Genton E, Reeves JT. Platelets are not essential for the pulmonary vascular response to hypoxia. J Lab Clin Med 1976;88:412-6.

15 Nenci GG. Platelets, hypoxaemia and pulmonary hypertension. Adv Exp Med Biol 1984;160:325-33.

16 Gensini GF, Rostagno C, Pezza A, et al. Effects of Dipyridamole infusion on local platelet aggregation and Dipyridamole infusion on local platelet aggregation and
local formation of Thromboxane A2 in patients with pulmonary hypertension. In: Neri Serneri GG, McGiff JC, Paoletti R, Born GVR, eds. Advances in Prostaglandin, thromboxane and leukotriene research. New York: Raven Press, 1985;13:257-62. 